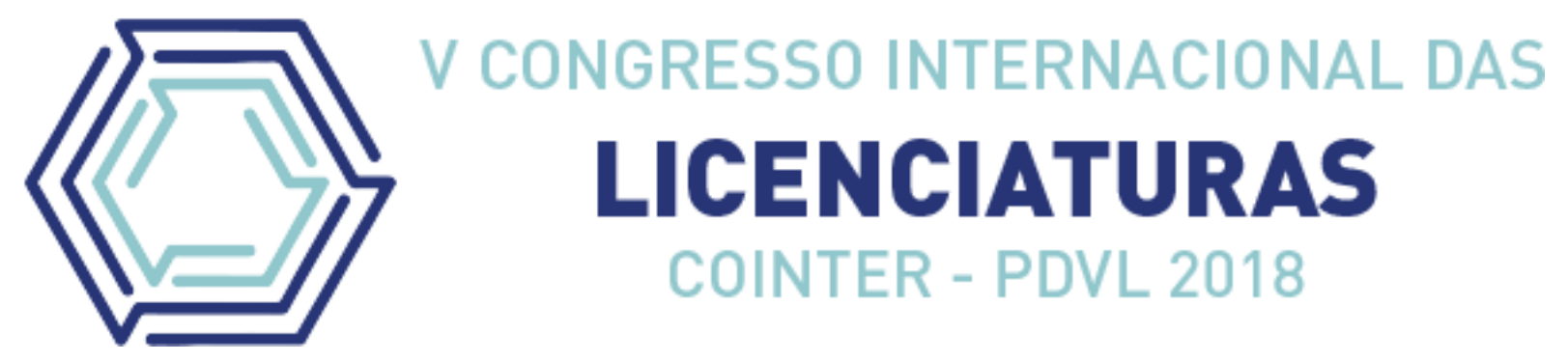

\title{
EXPERIMENTO DE OBTENÇÃO DO OXALATO DE POTÁSSIO CONTEXTUALIZADO AO ENSINO DA QUÍMICA VERDE
}

\section{LABORATORY EXPERIMENT WITH POTASSIUM OXALATE CONTEXTUALIZED TO THE TEACHING OF GREEN CHEMISTRY}

\author{
Apresentação: Relato de Experiência \\ Márcio Jean Fernandes Tavares ${ }^{1}$; Andréa do Oriente Lino ${ }^{2}$; Carlos Alberto da Silva \\ Júnior $^{3}$
}

\section{DOI: https://doi.org/10.31692/2358-9728.VCOINTERPDVL.2018.00279}

\section{Introdução}

Nesse trabalho objetivou-se o aprendizado e a compreensão, de forma mais significativa, do assunto prevenção e síntese de produtos menos perigos, que são, respectivamente, o primeiro e o terceiro princípio da Quimica Verde (QV) com alunos de uma escola pública. Para tal, foi realizado um experimento para obtenção do oxalato de potássio $\left(\mathrm{K}_{2} \mathrm{C}_{2} \mathrm{O}_{4}\right)$. As Orientações Curriculares para o Ensino Médio preconizam o desenvolvimento de "atitudes compromissadas com o ideal de cidadania planetária, na busca de preservação ambiental do ponto de vista global” (BRASIL, 2006, p. 115) mas muitos docentes, principalmente no Ensino de Química, têm negligenciando a abordagem desse tema, alegando falta de tempo e escassas publicações científicas dedicadas ao tema.

Sendo assim, esse trabalho propõe uma práxis abordando conceitos da $\mathrm{QV}$, que tem suas raízes na mudança de paradigma de gestão das medidas para proteção ambiental desenvolvidas pela indústria (MACHADO, 2011) e abrange o desenvolvimento de ações científicas ecologicamente corretas (CGEE, 2010). Como afirma Sousa-Aguiar (2014, p.127) ela "tem por objetivo a viabilização de processos e produtos de maneira a evitar ou minimizar o impacto negativo causado ao homem e ao meio-ambiente". Além do citado experimento, foram realizadas aulas dialogadas e participativas. A avaliação foi realizada pela análise da fala dos alunos e por meio de um Questionário de Sondagem (QS) e Final (QF) com questões abertas e fechadas.

\footnotetext{
${ }^{1}$ Licenciatura em Química, IFPB Campus João Pessoa, marciojeanftavres@gmail.com

${ }^{2}$ Licenciatura em Química, IFPB Campus João Pessoa, andreaoriente@gmail.com

${ }^{3}$ Licenciado e Mestrando em Química, UFPB Campus João Pessoa, carlosilva@ct.ufpb.br
} 


\section{Relato de Experiência}

A presente pesquisa foi realizada com 35 alunos de uma turma do $2^{\circ}$ ano do Curso de Técnico em Mecânica Integrado ao Ensino Médio no Instituto Federal de Educação, Ciência e Tecnologia da Paraíba, campus João Pessoa, localizado no Estado da Paraíba, em um total de três encontros. A metodologia usada foi amparada nos pressupostos de uma pesquisa participante e qualitativa (SCHMIDT, 2006).

No primeiro momento, aplicou-se um questionário de sondagem (QS). Por meio deste instrumento, pode-se verificar qual a percepção do alunado mediante ao tema proposto. Apenas $48 \%$ da turma respondeu corretamente ao QS, logo, escolheu-se começar a aplicação do projeto com uma discussão envolvendo os doze princípios da QV. No segundo encontro, com o intuito de se trabalhar de forma prática o ensino preconizado, preparou-se um experimento, no qual de forma participativa debateu-se os benefícios em trabalhar com processos industriais mais limpos e compromissados com a sustentabilidade. Para essa experimentação utilizou-se os materiais e reagentes elencados: bécker, espátula, água destilada, hidróxido de potássio $(\mathrm{KOH})$, oxalato de amônio $\left.\left(\mathrm{NH}_{4}\right)_{2} \mathrm{C}_{2} \mathrm{O}_{4}\right)$, ácido oxálico $\left(\mathrm{H}_{2} \mathrm{C}_{2} \mathrm{O}_{4}\right)$, indicador ácido-base fenolftaleína e luvas. Para a produção do oxalato de potássio $\left(\mathrm{K}_{2} \mathrm{C}_{2} \mathrm{O}_{4}\right)$ utilizou-se duas reações distintas, uma utilizando o oxalato de amônio $\left.\left(\mathrm{NH}_{4}\right)_{2} \mathrm{C}_{2} \mathrm{O}_{4}\right)$ e o hidróxido de potássio (ZHAO et al., 2007), e outra com o ácido oxálico $\left(\mathrm{H}_{2} \mathrm{C}_{2} \mathrm{O}_{4}\right)$ e o hidróxido de potássio $(\mathrm{KOH})$.

As reações são as seguintes:

$$
\begin{gathered}
\text { Reação simplificada 1: } \\
\left(\mathrm{NH}_{4}\right)_{2} \mathrm{C}_{2} \mathrm{O}_{4}+2 \mathrm{KOH} \cdot \mathrm{K}_{2} \mathrm{C}_{2} \mathrm{O}_{4}+2 \mathrm{NH}_{4} \mathrm{OH} \\
\text { Reação simplificada 2: } \\
2 \mathrm{H}_{2} \mathrm{C}_{2} \mathrm{O}_{4}+2 \mathrm{KOH} \cdot \mathrm{K}_{2} \mathrm{C}_{2} \mathrm{O}_{4}+2 \mathrm{H}_{2} \mathrm{O}
\end{gathered}
$$

Questionou-se aos alunos: "Qual rota deveria ser escolhida para a produção do oxalato de potássio? E o porquê??". O alunado respondeu, em sua grande maioria, que a reação 2 deveria ser escolhida, pois a mesma se enquadra nos princípios de prevenção ( $1^{\circ}$ princípio) e de síntese de produtos menos perigosos ( $3^{\circ}$ princípio), vistos anteriormente em sala de aula. A primeira reação produz o oxalato de potássio (ZHAO et al., 2007) e o hidróxido de amônio, que, apesar de ser uma base solúvel e fraca, é nociva quando inalada ou absorvida pela pele, podendo prejudicar os sistemas respiratório e cutâneo (IFA, 2016). Por 
outro lado, a segunda reação apenas produz o oxalato de potássio e a água, que é o solvente universal e, obviamente, não apresenta risco à saúde. Para a comprovação de que na reação 1 foi formada uma base forte (hidróxido de potássio), além do produto desejado, colocou-se 3 gotas do indicador ácido-base fenolftaleína, que deixou a solução em cor rosa (IFA, 2016). No outro béquer, que cotinha o oxalato de potássio e a água, também se adicionou o indicador, e a solução ficou incolor. Durante toda a aplicação a participação dos discentes foi muito importante, eles se mostraram entusiasmados e participativos. A sequência didática das aulas está ilustrada na Figura 1:

Figura 1: Sequência didática das aulas. Fonte: Própria

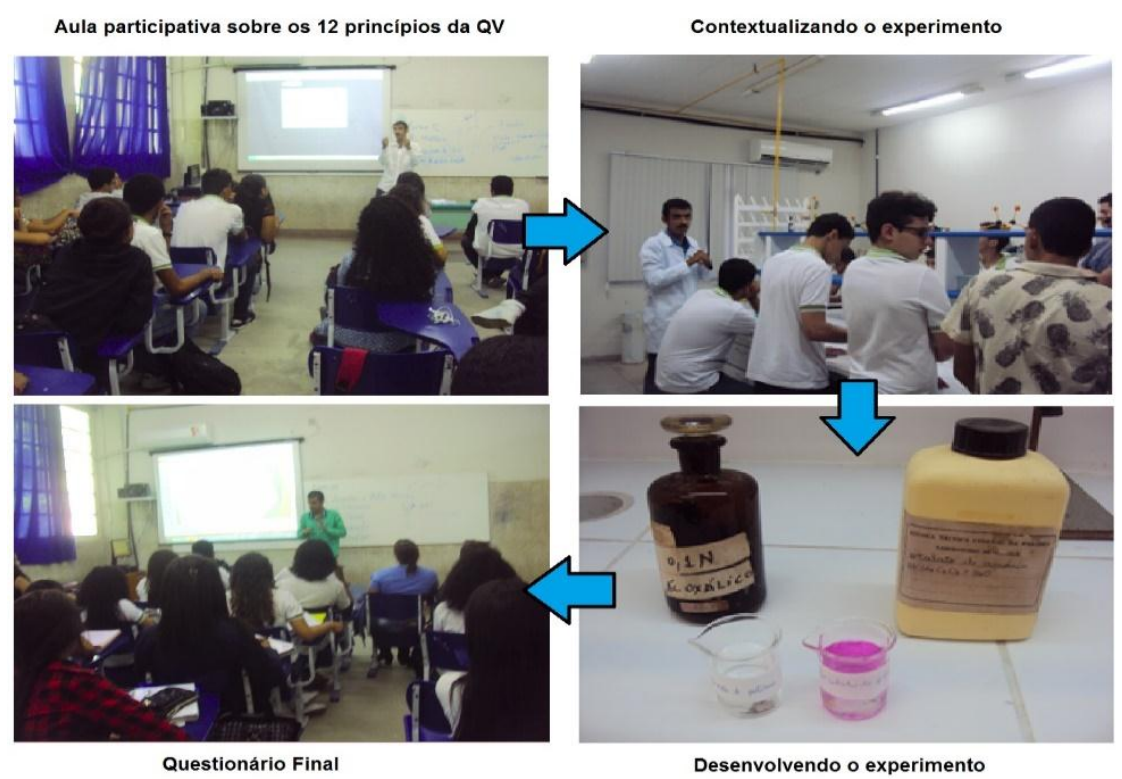

Na realização dessa atividade, pode-se verificar a importância de se escolher bem os reagentes na redução de produtos indesejados ou nocivos. Os discentes souberam identificar qual dos métodos de obtenção do oxalato de potássio $\left(\mathrm{K}_{2} \mathrm{C}_{2} \mathrm{O}_{4}\right)$ era o mais "verde", e como os princípios da QV os ajudaram nessa conscientização (FARIAS; FÁVARO, 2011). No início dessa pesquisa, muitos alunos não conseguiam, ao menos, relacionar a QV com o seu dia-adia, mas logo após esse diálogo processual e formativo, e também com a realização de um experimento, a maioria conseguia debater os benéficos dessa abordagem. É válido ressaltar que neste processo de formação o importante não é a repetição mecânica de uma definição, mas a compreensão do valor dos sentimentos, das emoções, da insegurança a ser superada pela segurança, do medo que, ao ser "educado", vai gerando a coragem. (FREIRE, 2015). O mencionado experimento teve como foco mostrar a importância de escolher uma reação que obedeça aos princípios da QV. Nesse caso, é mais viável evitar a formação de resíduos 
nocivos, como o hidróxido de amônio, do que tratá-los mais tarde.

No terceiro encontro, foi aplicado o QF, com questões abertas e fechadas. Os resultados foram de $100 \%$ de acertos. Um discente afirmou: "É muito interessante saber que a Química não está apenas associada com reação que gera lixo (...) ela se preocupa com o meio ambiente.". Sob esse viés, percebe-se o aprendizado da sinergia entre o Ensino de Química e o caráter socioambiental da atividade proposta.

\section{Considerações}

Em consonância com o exposto, a metodologia utilizada é relativamente simples e alternativa, podendo ser empregada em outras aulas experimentais para se discutir temas como catálise e reação química. Os resultados alcançados deixaram perceptível sua eficácia na compreensão do conteúdo abordado, fazendo com que os alunos visualizassem na prática o conceito de prevenção e síntese de produtos menos perigosos. Além disso, tal experiência aproximou os licenciandos participantes dessa pesquisa do seu futuro ambiente de trabalho, contribuindo para sua formação crítica e sustentável como educador.

\section{Referências}

BRASIL. Orientações Curriculares para o Ensino Médio: Ciências da Natureza, Matemática e suas Tecnologias. Secretaria de Educação Básica. - Brasília: Ministério da Educação, Secretaria de Educação Básica, 2006.

CGEE - Centro de Gestão e Estudos Estratégicos; Química Verde no Brasil 2010-2030, CGEE: Brasília, 2010 (ISBN 978-85-60755-31-8).

FARIAS, L. A.; FÁVARO, D. I. T. Vinte Anos De Química Verde: Conquistas E Desafios. Química Nova, vol. 34 (6), p.1089-1093, 2011.

IFA - Institute for Occupational Safety and Health Ammonia aqueous solution Disponível em:

http://gestisen.itrust.de/nxt/gateway.dll/gestis_en/001750.xml?f=templates $\$ f n=$ default.htm $\$ 3$. 0 Acesso em: 26 outubro 2016.

MACHADO, A. A. S. C.; Da gênese ao ensino da química verde, Química Nova, vol. 34 (3) p. 535-543, 2011.

SCHMIDT, M. L. S.; Pesquisa participante: alteridade e comunidades interpretativas. Psicologia USP, v. 17, n. 2, 11-41, 2006. 
SOUSA-AGUIAR, E. F.; et. al. Química Verde: A Evolução de um Conceito. Química Nova, vol. 37 (7) p. 1257-1261, 2014.

ZHAO H. K.; et al., (Solid + Liquid) Phase Diagram for the Ternary Potassium Oxalate + Hydrogen Peroxide + Water System at 283.15 K and 293.15 K. Journal of Chemical \& Engineering Data, 52 (4), 1386-1389, 2007. 